EESTI NSV TEADUSTE AKADEEMIA TOIMETISED. VIII KOIDE
BIOLOOGILINE SEERIA. 1959, NR. 4

ИЗВЕСТИЯ АКАДЕМИИ НАУК ЭСТОНСКОЙ ССР. ТОМ VIII СЕРИЯ БИОЛОГИЧЕСКАЯ, 1959, № 4

\title{
О РАСПРОСТРАНЕНИИ НЕКОТОРЫХ РЕДКИХ ТРУТОВЫХ ГРИБОВ
}

\author{
Э. ППАРMACTO, \\ кандидат биологических наук
}

Во время полевых работ в Коми АССР (в 1957 г.) и в Красноярском крае (в 1958 г.) автору удалось обнаружить некоторые интересные трутовые грибы. Из них один (Tyromyces crustulinus) является новым для CССР видом, второй (Meruliopsis semitincta) - новым для Евразиатского материка, а третий (Inonotus Heinrichii) - новым для Европы. Изучение имеющегося гербарного материала и литературы позволяет сделать некоторые выводы о систематике и своеобразном распространении этих видов, а также - впервые на русском языке - дать их полные описания.

Автор приносит свою благодарность Н. Т. Қартавенко, любезно предоставившей для опубликования свои данные о местонахождениях вида Inonotus Heinrichii.

Inonotus Heinrichii (Pil.) Bond. et Sing. in Ann. Myc., 39, p. 56 (1941); Pil. Atl. Polyp., p. 575 (1942); Бонд. Трут. гр., стр. 329 (1953). - Xanthochrous glomeratus (Peck) Pil. subsp. Heinrichii Pil. in Bull. Soc. Myc. Fr., 48, p. 28 (1932). - Xanthochrous Heinrichii Pil. in Bull. Soc. Myc. Fr., 49.. p. 272 (1934); 51, p. 375 (1935); 52, р. 317 (1936); Мурашк. Тр. Омск. Ин-та сельск. х-ва, 17, стр. 93 (1939). - Xanthochrous polymorphus (Rostk.) Bourd. et Galz. forma, Bourd. in Bull. Soc. Myc. Fr., 48, p. 229 (1932).

I c o n.: Pil. in Bull. Soc. Myc. Fr., 48, p. 28. f. 4 (1932); Pil. Atl Polyp., tab. 359 (1942).

Плодовые тела однолетние, распростертые, изредка узловатые, 5-15 см в диаметре, иногда сливающиеся и до 0,5 м длины, в середине 5-15-(20) мм толщины, к краям утончающиеся, мягко-пробковые, в сухом виде довольно ломкие, обычно плотно прикрепляющиеся, но иногда довольно легко отделимые, на нижней поверхности зональные. Край $1-3$ (в начале до 10) мм ширины, довольно толстый, лопастный, мохнатый или бархатистый, слегка радиально волокнистый, беловатый, рыжеватожелтый или желтовато-рыжий, потом рыжеватый, под конец одного цвета с остальной поверхностью. Подстилка $1-5$ (местами до 10) мм толщины, мягко-пробковая или губчатая, волокнистая, ржаво-бурая или красновато-бурая. Трубочки у краев плодового тела очень короткие, в середине 3-10 мм длины, нередко косые, изредка неясно слоистые, красновато-бурые, внутри с сероватым налетом, с перегородками 45-90 $\mu$ толщины. Поры у краев извилисто-сетчатые, к середине округло-угловатые, $(0,1)-0,15-0,3-(0,5)$ мм в диаметре, $3-4-(5)$ на 1 мм, с нежно бахромчатыми, нередко одновременно зубчатыми краями, поверхность 
трубчатого слоя цвета какао с лиловатым оттенком, в сухом виде ржавобурая, коричнево-бурая или (реже) светло-бурая, с сероватым налетом и серебристым отливом (фото 1,2$)$.

Гифы подстилки довольно плотно более или менее параллельно сплетенные, коричневые, более или менее тонкостенные, немного разветвленные, с перегородками, но без пряжек, 3-6 $\mu$ толщины; среди них встречаются бесцветные тонкостенные гифы $3-4 \mu$

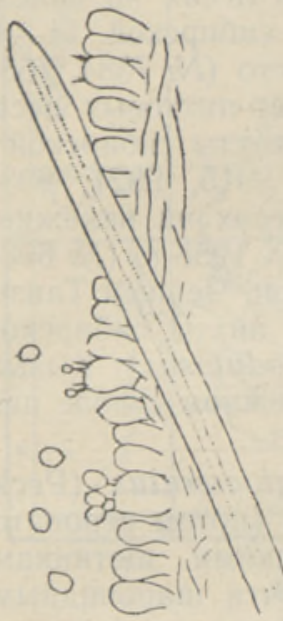

Pис. 1

Inonotus Heinrichii.

Часть гимения в разрезе (увел. $450 \times)$. толщины и (особенно под трубочками) темнокорнчневые толстостенные щетинковидные гифы до $9 \mu$ толщины. Иногда около самого субстрата наблюдается плотно склеенный слой темно окрашенных гиф.

Основная масса ткани трубочек состоит из прямых длинных темно окрашенных толстостенных щетинковидных гиф 5-10 $\mu$ толщины, выступающих своими несколько более толстыми (до $13 \mu)$ концами в виде щетинок. Среди щетинковидных встречаются и рыжеватые более тонкостенные гифы 2,5-5 $\mu$ толщины, снабженные перегородками. Субгимениальные гифы немногочисленные, бесцветные, тонкостенные. Щетинки тупо заостренные, иногда на верхушке несколько инкрустированные, выступающие до $15-30 \mu$ над гимениальным слоем. Базидии вздуто-булавовидные, не образующие плотного гимения, $8-18 \times 5-6,5 \mu$, с 4 стеригмами 1,5-2,5 $\mu$ длины. Споры эллипсондальные, с одной стороны плосковатые, бесцветные или едва желтоватые, $4-5-(6) \times(2,8)-$ $-3-3,5-$ (4) $\mu$ (рис. 1,2 ; фото 1,2 ).

Гниль древесины волокнистая, потом явно коррозионная; гниение древесины интенсивное.

f. nodulosus Pil. in Bull. Soc. Myc. Fr., 51, p. 376 (1935); Atl. Polyp., p. 576 (1942). Плодовые тела более толстые (до 2 см), с узловатой поверхностью (с зачаточными шляпками).

М естооби тан и е. На валежных стволах и пнях хвойных пород (Abies sibirica, Picea obovata, Larix sibirica, peжe Pinus sibirica, P. silvestris).

Р а с п р ост р ан ен и е. Ср. и Зап. Сибирь, Урал, Коми АССР; в Сибири встречается нередко, на западе - весьма редко.

М естон ахождения. Коми А С Р : Қаджиром, в лиственничном лесу на валежном стволе ели, собр. 21 VIII 1957 г. Э. Пармасто (№ 8505); Усть-Куломский район, верхн. течение реки Сорд-Ёль, в ельнике-кисличнике на валежном стволе ели, собр. 13 VIII 1957 г. Э. Пармасто (№ 8296, 8297). С в е р д л о в ск а я о бл.: Сев. Урал, Ивдельский район; Сев. Урал, в заповеднике «Денежкин камень»; район Нижние Серги (все три местонахождения Н. Т. Қартавенко). Но воси би р ская обл.: Сузинский массив, на сибирской лиственнице, собр. IX 1932 г. Ф. Соловьев (герб. БИНа). О м с к а я о л.: Тара, на пихте сибирской, собр. IX 1929 г. М. К. Зилинг

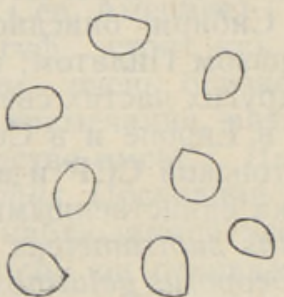

Рис. 2.

Inonotus Heinrichii. Споры (увел. $1000 \times)$. (Bourdot, 1932, p. 229; Pilát, 1932, р. 31). Т о м с к а я о бл.: Васюгане, на древесине ели сибирской, 26 IX 1934 г.; там же, на древесине 
сосны, VIII 1934 г.; Нарым, на древесине сосны (f. nodulosus Pil.), 20 IX 1934 г. (все три местонахождения Б. И. Кравцева) (Pilát, 1935 , р. 375-376). К р а с о я рский к р й: Хакассия, на древесине лиственницы сибирской, собр. ХІІ 1931 г. Б. И. Кравцев; в Саянах у реки Кантегир, на лиственнице, собр. IX 1932 г. Б. И. Кравцев (Pilát, 1934, p. 272); Минусинский район, на древесине лиственницы сибирской, собр. 1 IX 1935 г. Б. И. Кравцев (Pilát, 1936, p. 317); Ярцевский район, Кольчим, в кедрово-пихтовых и елово-пихтовых лесах на валежных стволах пихты сибирской, кедра сибирского и ели сибирской, $11-15$ VIII 1958 г., собр. (как и все последующие) Э. Пармасто (№ 7684, 7685, $7688,9769,9775,9858)$; заповедник «Столбы», в елово-пихтовых лесах на валежных стволах и пнях лиственницы сибирской, пихты сибирской и ели сибирской, 10-11 IX 1958 г. (№ 6903, 8959, 9915, 9921, 9931, 9956); Манский район, Баджей, в пихтово-еловых лесах на валежных стволах пихты сибирской и лиственницы сибирской, 6 IX 1958 г. (№ 6987, 9739, 9898; № 9737 - f. nodulosus); Ермаковский район, Черный Танзыбей, в кедрово-пихтовых лесах на валежных стволах пихты сибирской, 25 и 27 VIII 1958 г. (№ 7776, 9065, 9149; № 7775 - f. nodulosus); Қызылский тракт, Кулумыс, в пихтово-кедровом лесу на валежном стволе пихты сибирской, 30 VIII 1958 г. (№ 9420).

П ри меч ание. Близкий к I. Heinrichii вид I. glomeratus (Peck) Murr. отличается наличием шляпок, зеленовато-желтой (потом сероватой или бурой) поверхностью трубчатого слоя, более тонкими щетинками $(5-7 \mu$ толщины), более широкими $(3,5-4,5 \mu)$, почти шаровидными спорами, однородной, не коррозионной гнилью и субстратом (лиственные породы). Другой близкий вид I. radiatus (Fr.) Karst. отличается такой же гнилью и субстратом, наличием шляпок, более широкими $(3-4-(4,5) \mu)$ спорами, отсутствием ясно выраженных щетинковидных гиф и крючковидно загнутыми щетинками. Отличия от $I$. polymorphus (Rostk.) Bond. et Sing. см. стр. 269.

Лишь немногочисленные исследователи указывают размеры спор I. Heinrichii; даже в монографии самого Пилата (1942) эти данные отсутствуют (указаны только для f. nodulosus и то с двумя вопросительными знаками). У нашего материала споры немногочисленные, но встречаются почти всегда. Обильные споры удалось отметить у одного танзыбейского образца (№ 7776).

Как видно из списка местонахождений и рис. 3, I. Heinrichii имеет по сравнению с другими трутовыми грибами весьма ясно очерченный сравнительно небольшой ареал и встречается при этом внутри ареала довольно часто. Это - довольно редкое среди трутовых грибов явление. В Сибири описано немало новых видов трутовых грибов (главным образом Пилатом; см. Pilát, 1936-1942), но они или найдены позднее и в других частях света (например, Chaetoporellus Litschauerii (Pil.) Bond. - в Европе и в Сев. Америке; Gloeoporus tshulymicus (Pil.) Bond. - в Эстонской ССР и в Швеции), или находки типовых образцов являются пока единственными местонахождениями этих видов (например, Coriolellus subtrameteus (Pil.) Bond., Fomitopsis trametopora (Pil.) Bond., Gloeoporus gelatinoso-tubulosus (Pil.) Bond., G. Wasjuganicus (Pil.) Bond., Phellinus phellinoides (Pil.) Bond.).

Распространение I. Heinrichii в Сибири далеко еще не выяснено окончательно. Данные о микофлоре северной и восточной частей отсутствуют, и поэтому его настоящий ареал, по всей вероятности, доходит до северной и восточной границ распространения пихты сибирской или даже переходит их (см. ниже). Тем не менее ареал этот настолько интересен, что заслуживает внимания. Но для объяснения этого необходимо остано- 
виться на вопросе о происхождении I. Heinrichii, используя для этого сравнительно-морфологический, -анатомический, -экологический и -географический методы.

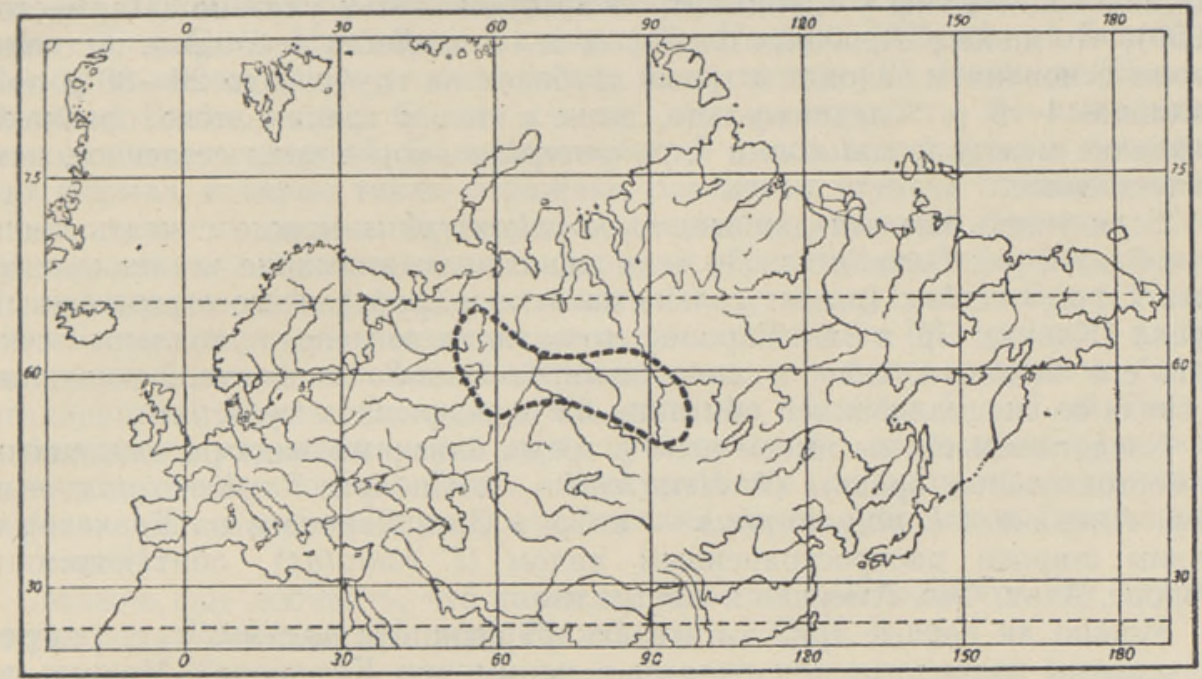

Рис. 3. Распространение Inonotus Heinrichii.

Род Inonotus включает не менее четырех видов, близких к I. Heinrichii. Заслуживает особого внимания наличие довольно редкого гистологического элемента в плодовых телах I. Heinrichii - щетинковидных гиф. Такие гифы встречаются еще, например, у I. nidus-pici Pil. Но последний отличается от I. Heinrichii многими другими признаками (отсутствие подстилки, маленькие поры, тонкие $(2-2,25 \mu)$ агглютинированные гифы, большие споры, субстрат - на древесине дуба, наличие стадии развития типа «чаги» и пр.) и принадлежит к одному ряду с I. obliquus (Fr.) Pil. Если учесть, что щетинковидные гифы встречаются и у некоторых видов рода Phellinus, то необходимо признать, что этот признак сам по себе не указывает еще на близкое родство I. Heinrichii с I. nidus-pici.

Иначе обстоит дело с I. glomeratus. Первоначально Пилат даже считал I. Heinrichii подвидом этого вида. Различия между ними ограничиваются лишь приведенными на стр. 268 признаками и разобщенностью их ареалов (I. glomeratus найден до сих пор только в Сев. Америке).

I. radiatus, якобы не имеющий щетинковидных гиф, стоит как по своему габитусу, так и многим частным признакам очень близко к I. Heinrichii. Как видно из приведенного на стр. 268 примечания, различия и здесь не особенно велики. Но еще большее сходство имеет I. Heinrichii с очень близким к $I$. radiatus видом $I$. polymorphus. Последний является обычно распростертым; в ткани трубочек наблюдаются узкие щетинковидные гифы длиною до $150 \mu$. От I. Heinrichii он отличается окраской, менее развитыми (в 10-15 раз более короткими!) щетинковидными гифами, большими спорами, типом гнили и субстратом.

Для получения общего представления о всей названной группе грибов необходимо еще остановиться на вопросе о взаимосвязи I. polymorphus и $I$. radiatus. I. polymorphus, растущий на ветвях бука и граба, отличается от распростертой формы I. radiatus (f. resupinatus Bourd. et Galz.) и от $I$. radiatus var. nodulosus (Fr.) Pil., также способных расти 
на буке, только наличием малоразвитых щетинковидных гиф и некоторыми второстепенными признаками. Пилат до 1940 г. считал I. polymorphus только синонимом разновидности I. radiatus var. nodulosus.

Что касается основного различительного признака - отсутствия щетинковидных гиф у I. radiatus, то автором статьи указано (Пармасто, 1959), что даже у типичных плодовых тел I. radiatus некоторые щетинки своим основанием заходят в траме трубочек на глубину до $20-80 \mu$ при толщине $4-6 \mu$. Следовательно, даже с точки зрения этого признака различие между $I$. radiatus и $I$. polymorphus скорее количественное, чем качественное.

Если учесть все эти данные, то I. polymorphus можно считать лишь одной из форм $I$. radiatus. Но если принять во внимание и специализацию I. polymorphus (растет только на буке и грабе) и его ограниченный ареал (Кавказ, Ср. и Зап. Европа), то кажется не менее правильным считать его молодым, едва отделившимся от I. radiatus видом, возникшим в связи со специализацией обитания на определенном субстрате.

Следовательно, мы имеем дело с тремя близкими видами, имеющими самостоятельные ареалы (I. Heinrichii - в Сибири, I. glomeratus - в Сев. Америке и I. polymorphus - в Ср. и.Зап. Европе и на Кавказе) и одним широко распространенным видом (I. radiatus), обитающим в Европе, Азии, Сев. Америке и Австралии.

Можно ли первые три считать викарирующими видами, т. е. географическими подвидами или видами в понимании Комарова? Можно, но эти понятия, заимствованные из терминологии распространения высших растений, здесь не совсем подходят. Фактором видообразования являлся здесь не какой-то неопределенный комплекс условий местообитания, обусловленный различиями в географической среде, а совершенно определенный фактор - субстрат. Ведь известно, что многие трутовые грибы очень широко распространены, почти космополитичны, а вариации, наблюдаемые у их плодовых тел в разных странах, меныше, чем таковые в одной стране, но на разных субстратах (напр., Phellinus pini (Fr.) Ames!). На подобную же закономерность, хотя и с другим объяснением, указано и Васильковым (1958, стр. 95).

Следовательно, изолированные ареалы I. Heinrichii, I. polymorphus и I. glomeratus обусловлены ареалами распространения их субстратов. Относительно I. polymorphus этот вопрос ясен. I. glomeratus встречается в Сев. Америке на клене и буке, а в меньшей мере и на́ других породах. Но чем объяснить сравнительно небольшое распространение I. Heinrichii, обитающего на н е к т о рых видах хвойных пород?

I. Heinrichii встречается на пяти видах хвойных пород, но подавляющее большинство местонахождений - на пихте сибирской. Особенно заметно это в тех районах, где он встречается чаще. Поэтому можно полагать, что I. Heinrichii обитал раныше только на пихте и лишь впоследствии приобрел способность питаться и на других субстратах.

В данном случае нет никакой необходимости искать гипотетического общего предка видов I. Heinrichii, I. glomeratus и I. polymorphus. Как морфологические и гистологические признаки, так и большой ареал распространения и «полифагия» у I. radiatus указывают, что именно этот вид является исходным для всей указанной группы грибов, в том числе и для I. Heinrichii. Ограниченное распространение последнего объясняется его происхождением как вида, специализированного к обитанию на древесине пихты сибирской. Если это так, то настоящий ареал I. Heinrichii, по всей вероятности, несколько обширнее ныне известного и доходит до границ распространения Abies sibirica или даже пересекает их.

Bсе изложенное являлось бы весьма гипотетическим, если на такое 
возникновение новых видов трутовых грибов путем специализации не указывали бы и взаимоотношения видов других групп рода Inonotus и, в частности, рода Phellinus.

В роде Phellinus известна группа более или менее узко специализированных видов, как бы сконцентрированных вокруг «полифага» Ph. igniarius (Fr.) Quél. Некоторые из них (Ph. Hartigii (Allesch. et Schnab.) Bond.) более отдалены от «исходного» вида, другие (Ph. tremulae (Bond.) Bond. et Boriss.) столь близки к нему, что правильность их выделения можно считать спорной. Большинство этих видов встречается в нескольких формах, которые также отражают различные ступени специализации и находятся на разных ступенях отдаления от «видовой формы». Как пример таких сильно отдаленных форм, не успевших еще сформироваться в самостоятельный вид, можно назвать $P$ h. igniarius f. sorbi Bond. Интересно отметить, что молодые, менее отличающиеся от Ph. igniarius виды, являются более узко специализированными, а у более старых и более отдаленных видов (например Ph. robustus (Karst.) Bourd. et Galz.) наблюдается уже расширение круга субстратов. Из этого можно сделать вывод, что возникновение новых видов трутовых грибов происходит путем чередования специализации и расширения круга субстратов (питающих растений).

Можно еще добавить, что такие же явления наблюдаются и у других видов рода Phellinus (Ph. pini, Ph. ribis (Fr.) Quél. и др.).

Каким образом происходит возникновение новых видов Inonotus н Phellinus - медленно, постепенно или в виде быстрого «скачка»? Судя по обилию всевозможных переходов - от едва заметного отклонения до хорошо различимых видов, - можно утверждать, что в данном случае этот процесс происходит медленно и постепенно. Тот факт, что «переселение трутовых грибов на новый субстрат не приводит к быстрому преобразованию их строения, зависит отчасти от того обстоятельства, что их специализация не является столь строгой, как, например, у ржавчинных или головневых грибов. Мы знаем много примеров, когда вид, обитающий на хвойных деревьях, может случайно расти и на лиственных породах и наоборот. Более того, мы даже не имеем никаких экспериментальных данных о том, являются ли такие узко специализированные виды, как Ph. tremulae, действительно наследственно устойчивыми или они способны уже в первом поколении потомства превращаться в «исходный» вид. Подобные эксперименты требуют много времени (10 лет или более), но без проведения их существующая концепция вида относительно Phellinus остается субъективной.

Tyromyces crustulinus (Bres.)E. Parmasto comb. nov. - Poria crustulina Bres. in Mycologia, 17, p. 75 (1925); Baxter in Pap. Mich. Ac. Sc., 22, p. 290 (1937); Gilbertson in Lloydia, 19, 3, p. 76 (1956); J. Eriksson in Symb. Bot. Upsal., 16, 1, p. 148 (1958).

I c o n.: J. Erikss. loc. cit., fig. 47.; pl. 22 C.

Плодовое тело однолетнее (по Бэкстеру, иногда многолетнее), распростертое, довольно плотно прикрепляющееся, неправильно округлое, 5-20 см в диаметре, 2-5 мм толщины, восковидное или водянистое, потом твердеющее, в сухом виде хрупкое. Край 0,5-2 (по Бэкстеру, до 4) мм ширины, пушистый или войлочный, белый или грязноватый, под конец исчезающий. Подстилка 0,3-1,5 мм толщины, белая, плотно-ватообразная. Трубочки 1-3 мм длины, нередко косые, с перегородками 45-90-(120) тые, неравновеликие, $0,2-0,5-(1)$ мм в диаметре, $2-4$, в среднем 3 на 
1 мм; края пор цельные или несколько зубчатые. Поверхность трубчатого слоя кремоватая, в сухом виде кремово-желтая, рыжевато-желтоватая, охряно-желтая или даже желтовато-рыжая, с бархатистыми переливами в зависимости от направления света (фото 3,4$)$.

Гифы подстилки рыхло-перепутанные, бесцветные, инкрустированные мелкими зернышками, $3-5 \mu$ толщины, одни толстостенные почти до сплошных, прямые, другие тонкостенные, более разветвленные, с пряжками. Гифы трубочек такие же, но более параллельно сплетенные, в общем более тонкостенные, с более частыми пряжками, $2,5-4,5-(5) \mu$ толщины. Субгимениальный слой $8-20-(30) \mu$ толщины. Базидии $12-20$ Х $\times 4,5-6 \mu$, с 4 стеригмами 2,5 $\mu$ длины; встречаются и цистидиолы. Споры бесцветные, цилиндрические, с одной стороны плоские или несколько согнутые, $(5,0)-5,2-6,5 \times 2,4-3 \mu\left(\frac{\text { длина }}{\text { шнрнна }}=1,9-2,4\right)$ (рис. 4,$5 ;$ фото 3,4$)$.

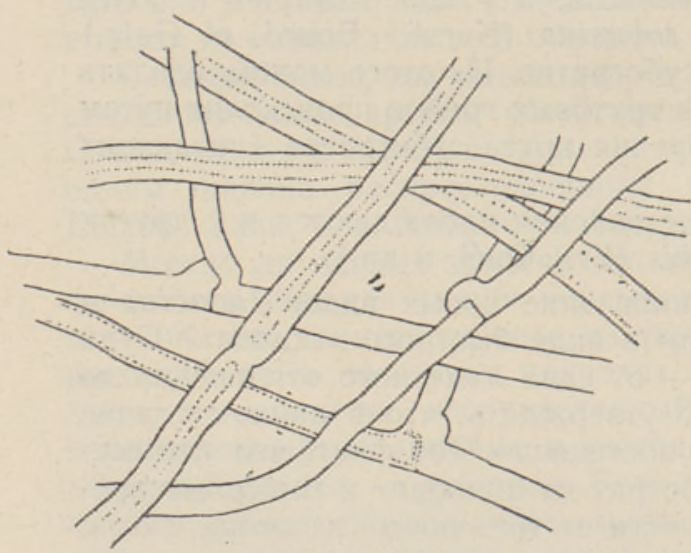

Рис. 4. Tyromyces crustulinus. Гифы подстилки (увел. 675Х).

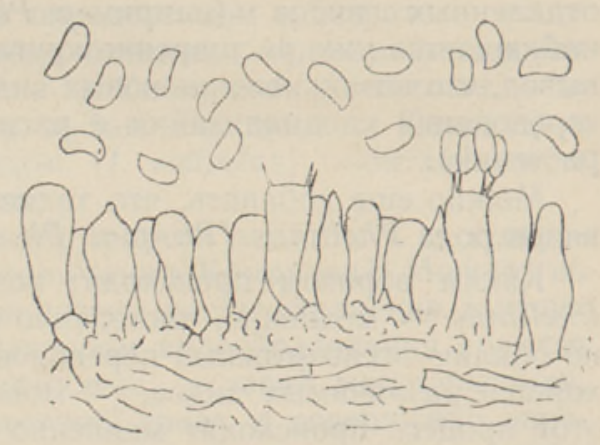

Рис. 5.

Tyromyces crustulinus.

Часть гимения в разрезе и споры (увел. $675 \times$ ).

M естообитани е. Растет на древесине хвойных пород (Abies, Picea, Pinus, Tsuga).

Р аспространени е. Сев. Америка (чаще в лесах средней Аляски), Сев. Европа (очень редко в Швеции и Финляндии), Ср. Сибирь. (Рис. 6.) Р аспр ост ра нен и е в С С С : Красноярский край, Енисейский (бывш. Ярцевский) район, у низовьев реки Кольчим (правый приток Сыма в 100 км от Енисея) в пихтово-елово-смешанных лесах на валежных стволах ели (Picea obovata), собр. 14 VIII 1958 г. (№ 9789) и 17 VIII 1958 г. (№ 9706) Э. Пармасто.

Пр и ме чания. По внешнему виду $T$. crustulinus имеет сходство с Tyromyces aneirinus (Sommerf.) Bond. et Sing.; последний отличается эллипсоидально-яйцевидными спорами $5,5-8 \times 3,5-4,2 \mu$ величины, большими порами - 0,3-1 мм в диаметре, тонкостенными гифами и обитанием на лиственных породах.

У обоих собранных образцов мы измерили при увеличении в 1350 раз 50 спор. Результаты: № 9706 - споры $(4,8)-5,2-6,3-(6,5) \times 2,4-$ $-3,0-(3,1) \mu$, в среднем $5,81 \pm 0,43 \times 2,70 \pm 0,21 \mu ; \frac{\text { длина }}{\text { ширина }}=(1,8)-1,9-$ $-2,4-(2,5)$, в среднем $2,16 \pm 0,16 \mu$. № 9789 - споры $(5,0)-5,2-$ $-6,2-(6,5) \times(2,3)-2,4-2,3-(2,9) \mu$, в среднем $5,63 \pm 0,38 \times 2,56 \pm 0,14 \mu$; $\frac{\text { длина }}{\text { ширина }}=(1,9)-2,0-2,4-(2,5)$, в среднем $2,24 \pm 0,14 \mu$. 


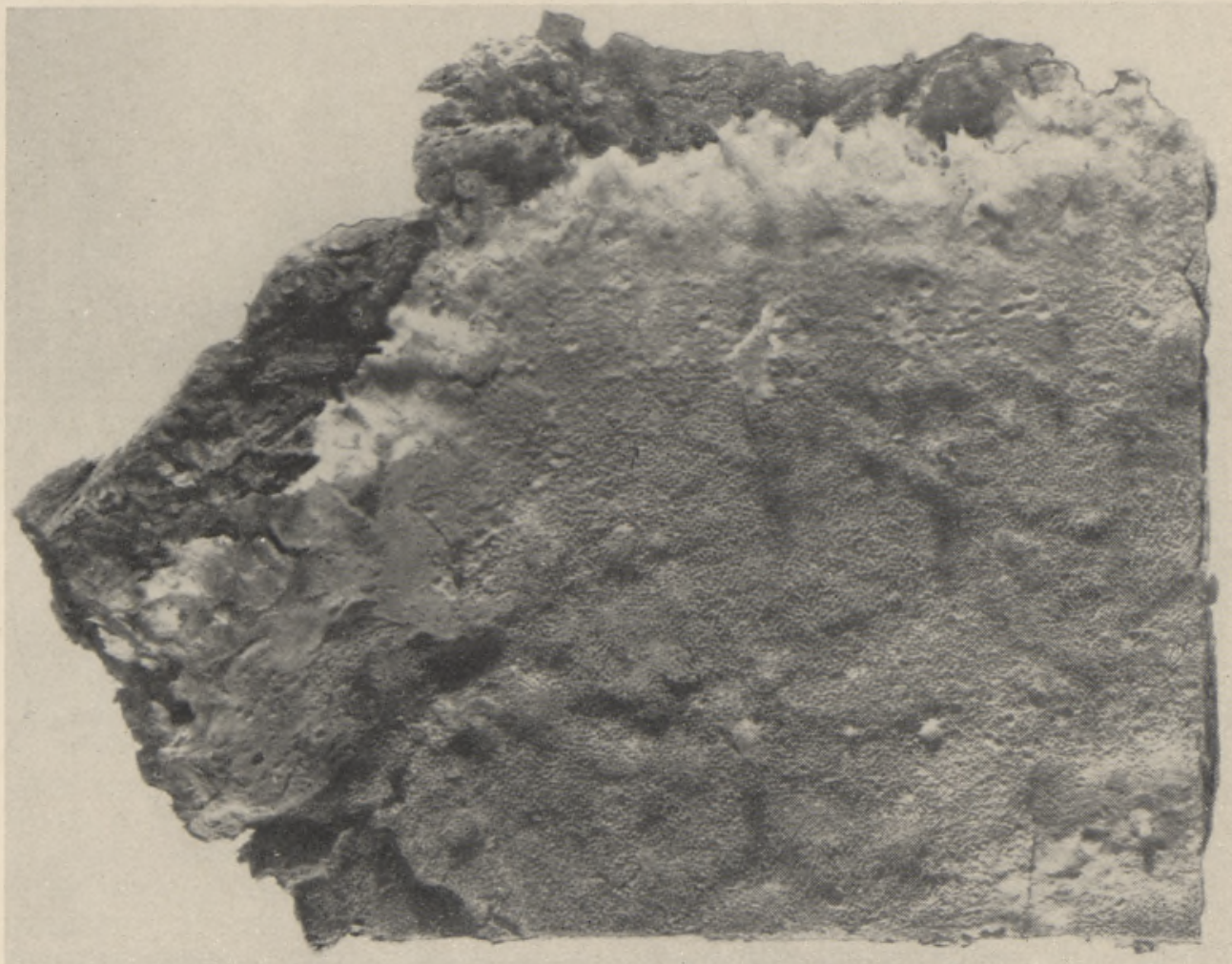

Фото 1. Плодовое тело Inonotus Heinrichii (увел. 1,8×).

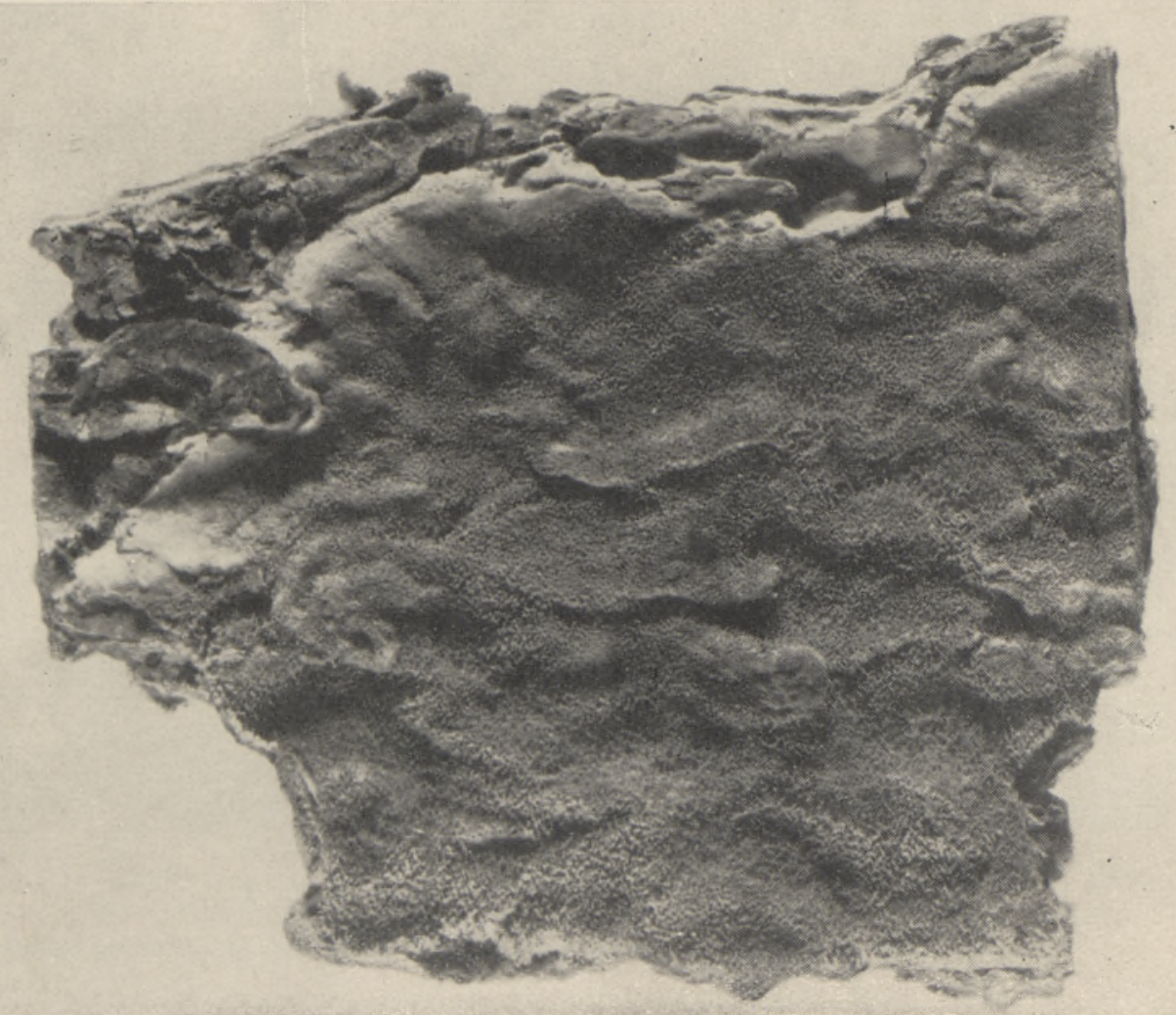

Фото 之. 1 Ілодовое тело Inonotus Heinrichii (увел. 1,6×). 


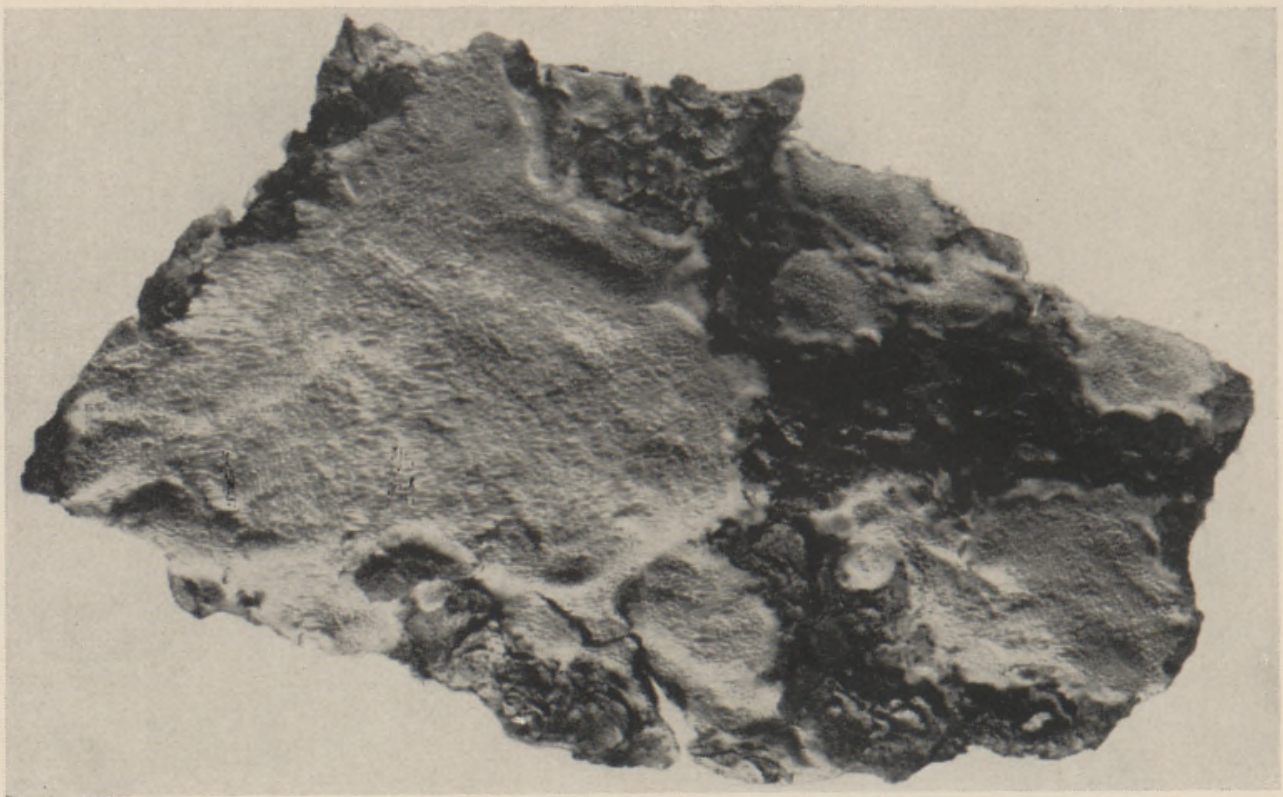

Фото 3. Плодовое тело Tyromyces crustulinus (увел. 1,4X).

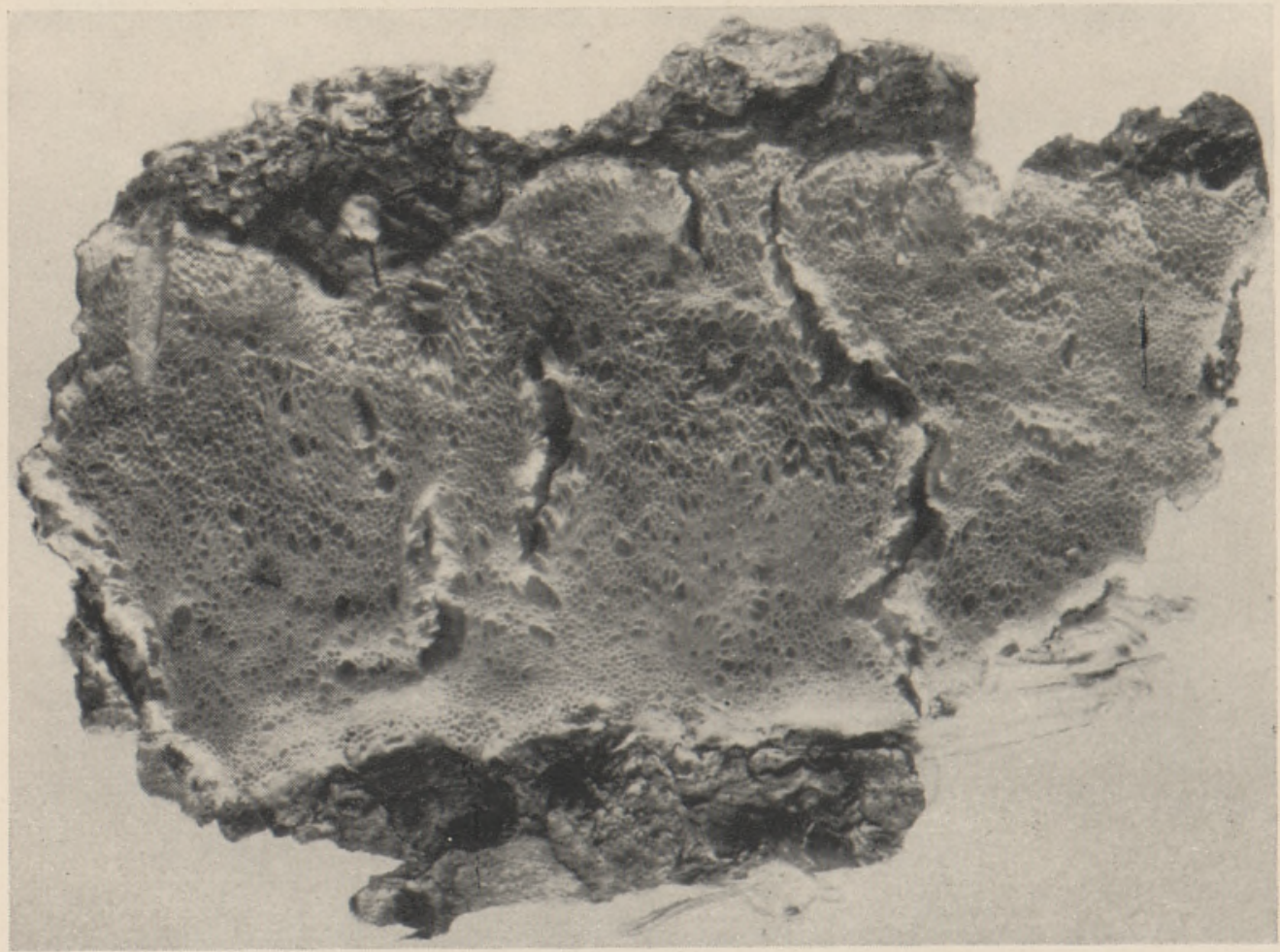

Фото 4. Плодовое тело Tyromyces crustulinus (увел. $2 \times$ ). 


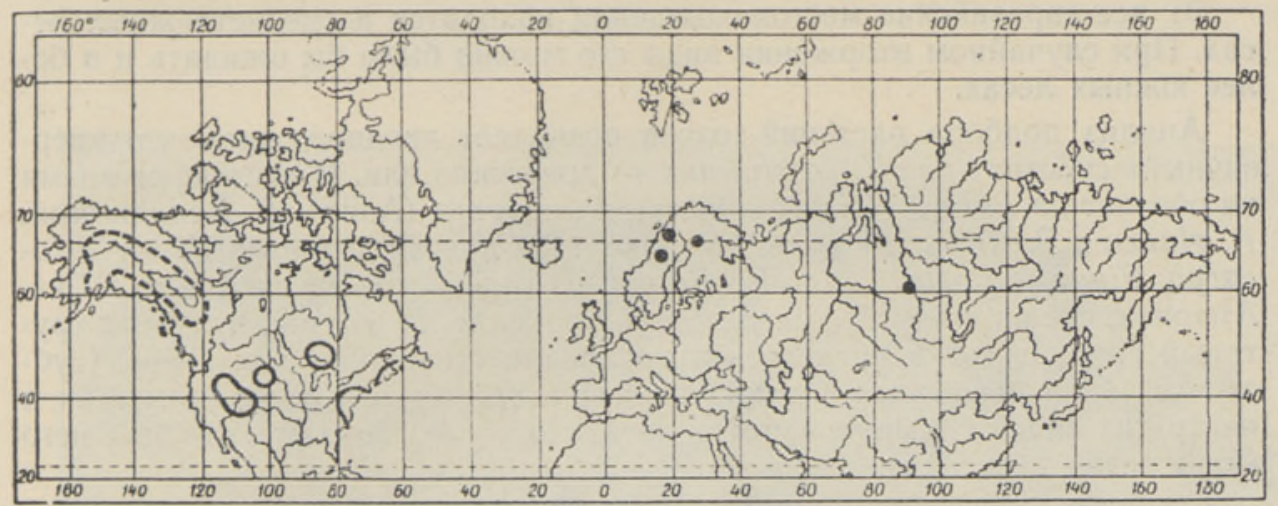

Рис. 6. Распространение Tyromyces crustulinus.

В связи с этими данными, позволяющими в будущем более основательно изучить варьирование вида в пределах его ареала, следует остановиться на некоторых вопросах методики микроскопического исследования и описания грибов.

Как известно, при указании размеров спор обычно не ссылаются ни на число измерений, ни на количество изученных плодовых тел. Это исключает возможность оценивать объективность указанных разными авторами численных данных и сравнения последних. Думается, что в таких случаях необходимо прийти к какому-нибудь соглашению и указать размеры спор для минимально необходимого количества, например на основе не меньше чем 50-ти измерений.

То же самое касается и оформления полученных данных. Даже в обстоятельном руководстве Жоссерана (Josserand, 1952) не указывается точно, какие крайние отклонения размеров следует приводить в скобках при описаниях. Автору кажется, что и здесь необходимо прийти к соглашению относительно какой-нибудь условной величины. Так, при приведении размеров спор предлагается указать в скобках крайние отклонения размеров, наблюдаемых у $10 \%$ измеренных спор. Например, «споры $(5,0)-5,2-6,2-(6,5) \mu$ длины» означало бы, что $10 \%$, спор имеют длину $5,0-5,2$ или $6,2-6,5 \mu$. Разумеется, возможны и другие подобные решения; по-видимому, этот немаловажный вопрос требует специального изучения и предложений, базирующихся на статистическом исследовании.

Географическое распространение $T$. crustulinus весьма интересно: он обитает в бореальных лесах Европы, Азии и Америки и везде (кроме Аляски и Канады) встречается редко (рис. 6). Почти такое же распространение свойственно еще Fomitopsis Stellae (Pil.) Bond., Chaetoporellus Litschauerii (Pil.) Bond., Ch. variecolor (Karst.) Рarm. и др. Все они принадлежат к таежному элементу (см. Пармасто, 1959). Чрезвычайно интересно редкое нахождение $T$. crustulinus в Евразии. Мы склонны рассматривать такое распространение вида как признак реликтового характера, : это по нижеследующим причинам:

1) во всех евразийских местонахождениях гриб встречается только единичными экземплярами. В случаях инвазии можно было бы ожидать нахождение его в большем количестве;

2) в Евразии T. crustulinus встречается только на ели, а в Сев. Америке - на разных хвойных породах. Если $T$. crustulinus являлся бы случайным пришельцем, то он попадался бы и на других хвойных; 
3) все евразийские местонахождения находятся в среднетаежных лесах. При случайном вторжении вида его можно было бы ожидать и в более южных лесах.

Анализ подбора растений-хозяев позволяет предположить, что жпервичный» субстрат для $T$. crustulinus - древесина ели. В настоящее время он обитает на Picea excelsa (Европа), P. obovata (Азия). P. Engelmannit. $P$. glauca и P. sitchensis (Сев. Америка). На других хвойных (Abies lasiocarpa, Pinus contorta, Tsuga heterophylla) гриб встречается только в Сев. Америке, где он имеет большее распространение. Думается, что если трутовый гриб растет в пределах всего ареала лишь на одном виде (субстрате) (или некоторых близких видах) и только в некоторых местах и на других видах, то можно утверждать, что последние являются для него вторичными хозяевами.

Meruliopsis semitincta (Peck) E. Parmasto comb. nov.* - Polyporus semitinctus Peck in 31-st Rep. New York State Mus., p. 37 (1879). Poria semitincta (Peck) Cke. in Grev., 14, p. 115 (1885); Baxter in Pap. Mich. Ac. Sc., 24, p. 180 (1939); Overh. in Penns. State Coll. School Agric. Agric. Stat. Tech. Bull., 418, p. 51 (1942); Lowe in Techn. Public. New York State Coll. Forestry, 65, p. 45 (1946); Gilbertson in Lloydia, 19, 2, p. 75 (1956). - Poria mutans tenuis Peck in 43-d Rep. New York State Mus., p. 39 (1898); Baxter in Pap. Mich. Ac. Sc., 28, p. 219 (1943).

Плодовые тела однолетние, распростертые, легко отделяющиеся, не сколько сантиметров в диаметре, потом распространяющиеся и сливающиеся, до 10-(20) см в диаметре, мягкие, пленковидные, очень тонкие (0,5-1,5 мм), в сухом виде хрупкие. Край паутинистый, радиально волокнистый, очень тонкий, широкий, 1-3-(10) мм ширины, позднее медленно исчезающий, белый, потом иногда с кремоватым или лиловатым оттенком. Подстилка тонкая $(0,2-1,0$ мм), мягко-ватообразная. Трубочки очень короткие (0,3-0,8 мм), восковидной консистенции, в сухом виде мягкие или хрупкие. Поры мерулиоидного типа, у краев сетчатые или даже в виде изолированных друг от друга чашечек, к середине угловато-округлые, неравновеликие, $0,2-0,4-(0,5)$ мм в диаметре, (2)-3-4 на 1 мм; края их цельные или (при рассмотрении под лупой) мелкореспитчатые. Поверхность трубчатого слоя ярко-фиолетовая, фиолетово-розовая или (реже) белая с фиолетовым оттенком, но иногда темно-кремовая и только кое-где около краев с фиолетовыми участками. При высыхании (в гербарии) плодовые тела обычно медленно приобретают совершенно другую окраску: их поверхность тогда инкарнатная, лососево-красная, охряно-желтая или даже желтовато-буроватая; слабый лиловатый оттенок сохраняется только местами и то не всегда (рис. 7,8 , фото $5,6,7$ ).

Гифы подстилки во всех направлениях рыхло перепутанные, разветвленные под прямым углом, тонкостенные, с перегородками, но без пряжек (по другим авторам с редкими пряжками), иногда несколько инкрустированные, 3-5,5-(7) $\mu$ в диаметре. Гифы трубочек плотно параллельно склеенные, сильно инкрустированные яично-желтым (в растворе $\mathrm{KOH}$ )

* MERULIOPSIS Bondarzew nom. nov. SYNONYMUM: Merulioporia Bond. et Sing. Сов. ботаника, 1, p. 38 (1943); Sing. in Mycol., 36, p. 67, 69 (1944); Бонд. Трут. гр., p. 51, 593 (1953). TYPUS: Xylomyzon taxicola Pers. Myc. Eur. II, p. 32 (1825). HOMONYMUM: Meruliporia Murr. in Mycol., 34, p. 596 (1942).

SPECIES: Meruliopsis taxicola (Pers.) Bond. comb. nov. Basonymum: Xylomyzon taxicola Pers. Myc. Eur. II, p. 32 (1825). Meruliopsis purpurea (Fr.) Bond. comb. nov. Basonymum: Polyporus purpureus Fr. Syst. Myc. I, p. 379 (1821). Meruitopsis violacea (Fr.) Bond. comb, nov. Basonymum: [Polyporus violaceus Fr. Obs. Myc. II, p. 263 (1818) nec alibi;] Poria violacea Bres, in Ann. Myc, I, p. 76 (1903). 


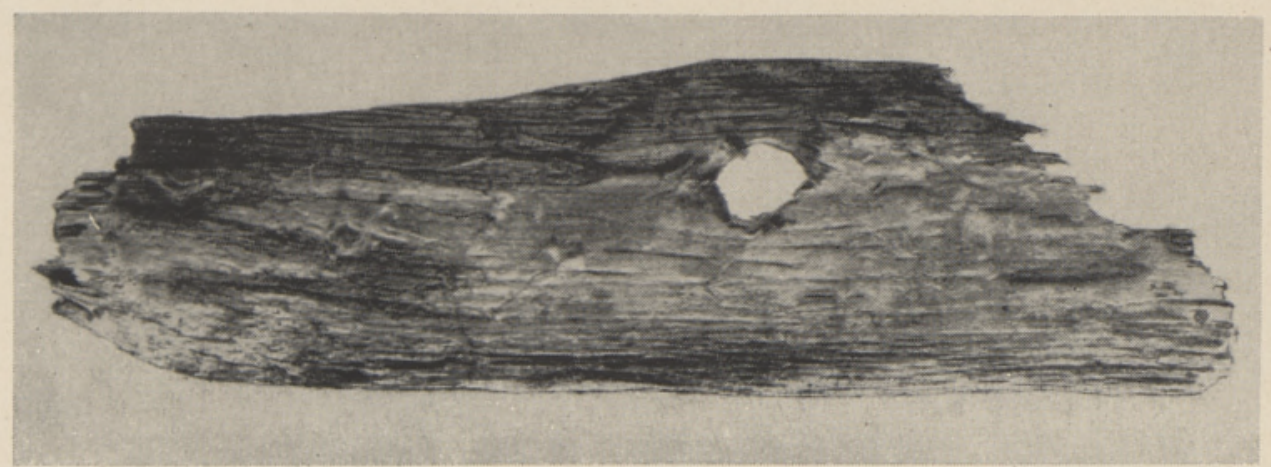

Фото 5. Плодовое тело Meruliopsis semitincta (уменьш. 0,9×).

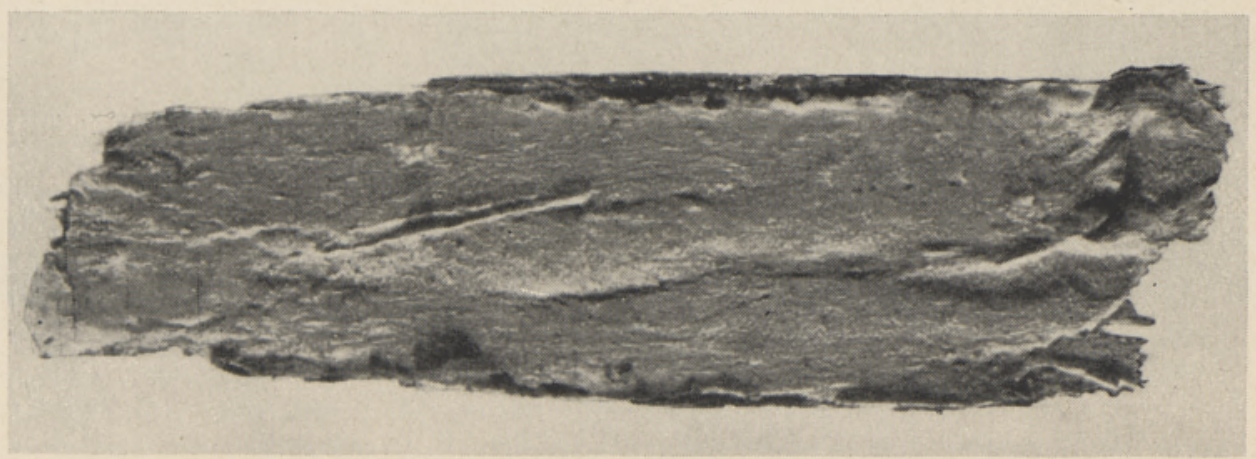

Фото 6. Плодовое тело Meruliopsis semitincta (увел. 1,25×). 


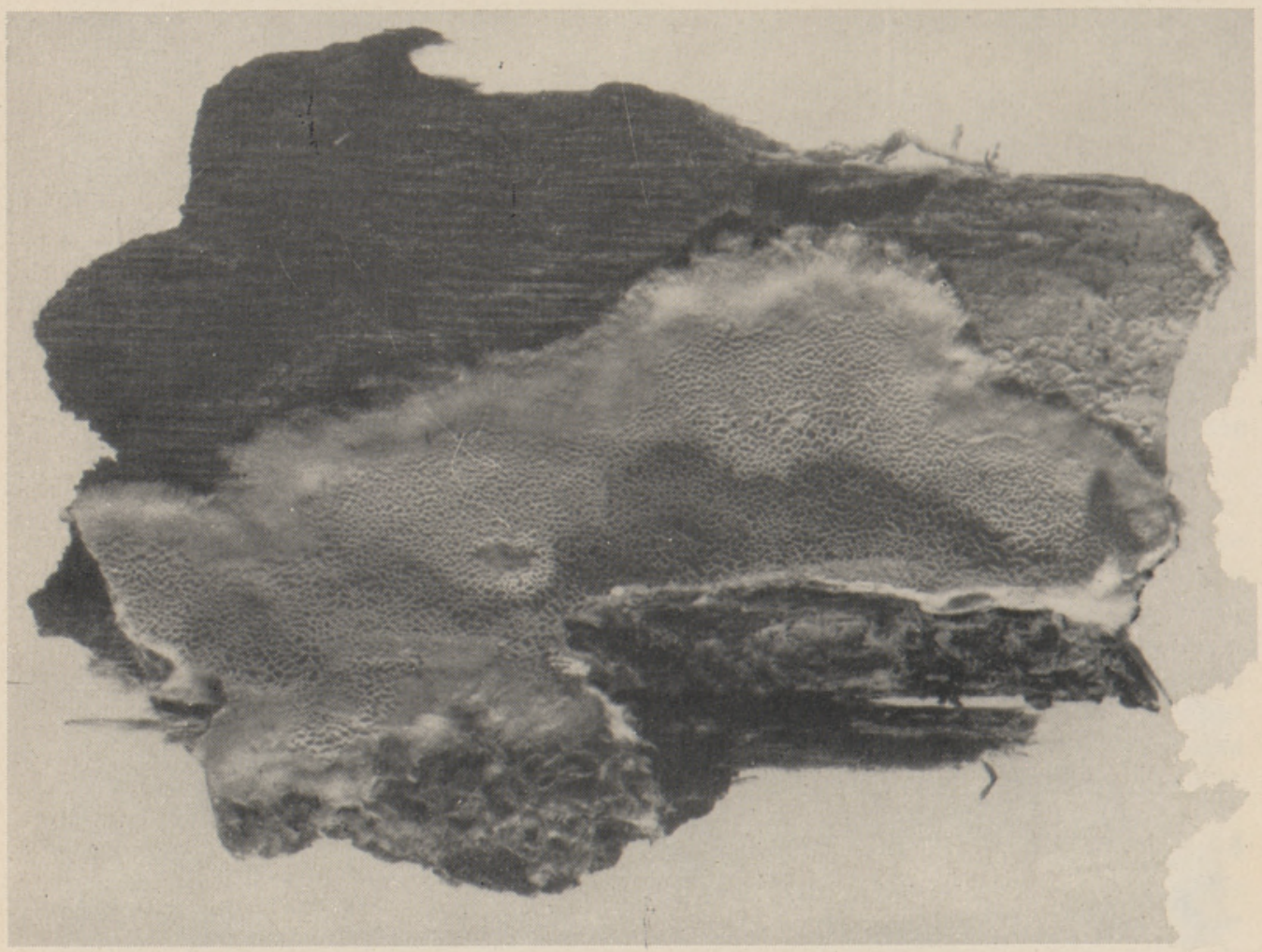

Фото 7. Плодовое тело Meruliopsis semitincta (увел. $3 \times$ ). 
смолистым веществом, 3-4,5 $\mu$ в диаметре. Гимениальный слой покрывает вначале и складки гименофора; позднее края пор стерильные, с выступающими иногда инкрустированными гифами $4-5 \mu$ толщины и $10-25 \mu$ длины. Базидии булавовидные, $12-20 \times 4,5-5,5 \mu$, с 4 стеригмами 4-6 д длины. Встречаются немногочисленные цистидиолы. Споры коротко-цилиндрические, с одной стороны плоские или несколько вогнутые. бесцветные, обычно с полярными капельками, $3,5-5-(6) \times 1,5-2-$ $-(2,3) \mu$ (рис. 7,8$)$.

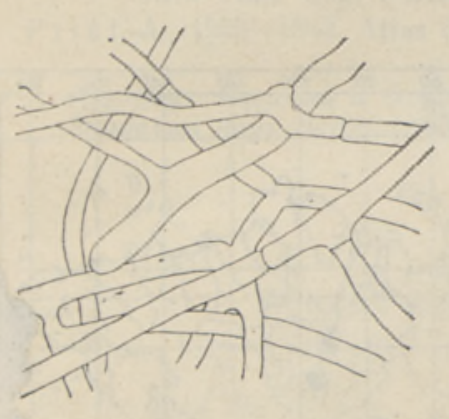

Рис. 7

Meruliopsis semitincta. Гифы подстилки (увел. $450 \times$ ).

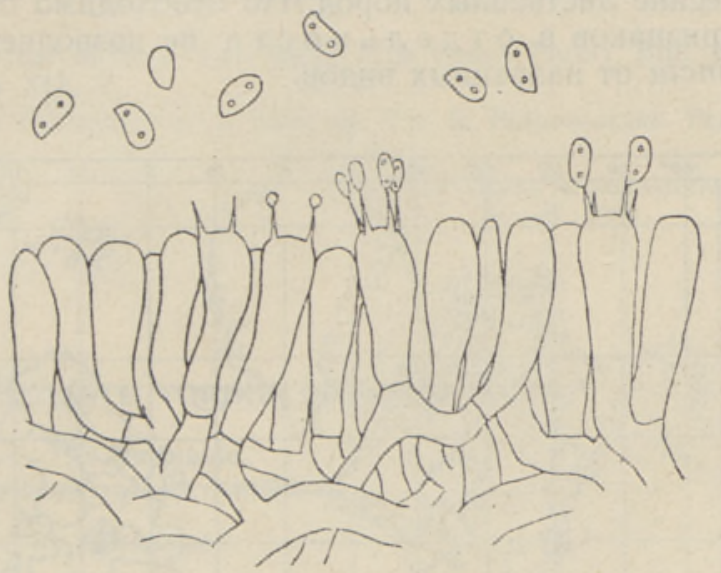

Рнс, 8. Meruliopsis semitincta. Часть гимения в разрезе и споры (увел. 1010Х).

7. нилая древесина распадается в пластинки по годичным слоям; гниль светлая (светло-коричневая, «белая»), волокнистая, позднее явно коррозионная.

3. с т о об и тан и е. В Сев. Америке на многих видах лиственных и 'с ых деревьев (Acer sp., Aesculus californica Betulasp., Castanea dentata, Irgius florida, Fagus grandiflora, Fraxinus sp., Nyssa sylvatica, Populus sp., Quercus alba, Q. imbricata, Q. macrocarpa, Q. marilandica; Taxus baccata); в Сибири на древесине пихты (Abies sibirica) и (одно местонахождение) на осине (Populus tremula).

Р а с п р ос тр а н е и е. В Сев. Америке (в сев.-вост. части США, в Калифорнии, в Британской Қолумбии и в центральной части южной Канады) и в Азии (в СССР). Р а с п р о с т р н е н и е в СССР - в средней и южной частях Красноярского края: в окрестностях устья реки Кольчим (правый приток р. Сым в 100 км от Енисея), в кедрово-пихтово-еловых лесах на валежных стволах пихты, 14 и 15 VIII 1958 г. (№ 7678, 9771, 9777, $9798,9799)$; в окрестностях Ярцева, в пихтово-еловом лесу на правом берегу Енисея на валежном стволе пихты 19 VIII 1958 г. (№ 9832); в Манском районе, ок. Кедрового (в 25 км к югу от пос. Нарвы), в березняке на валежном стволе осины 5 -IX 1958 г. (№ 9717); в Ермаковском районе, ок. Черного Танзыбея и Кулумыса в пихтово-кедровых лесах на валежных стволах пихты 25 и 30 VIII 1958 г. (№ 7789 и 9425) (все сибирские образцы собраны Э. Пармасто).

П р и м е ч н и е. Благодаря очень тонким плодовым телам и их своеобразной окраске определение $M$. semitincta в природных условиях не пред- 
ставляет трудностей. В гербарии окраска сильно изменяется и определение высушенного материала уже затруднительно. Быть может, именно вследствие этого этот широко распространенный в средней части Сибири вид остался до сих пор незамеченным.

Из близких к $M$. semitincta видов можно указать Ceraporia rhodella (Fr.) Donk, C. incarnata (Bres.) Bond. и Meruliopsis purpurea (Fr.) Bond. Bce они различаются окраской плодовых тел, формой и величиной спор, а первые два и с самого начала стерильными краями более длинных трубочек. Кроме того, C. rhodella и $M$. purpurea обитают на древесине лиственных пород. Но необходимо отметить, что ни один из этих признаков в о т д ел ь н о т и не позволяет четко отграничить $M$. semitincta от названных видов.

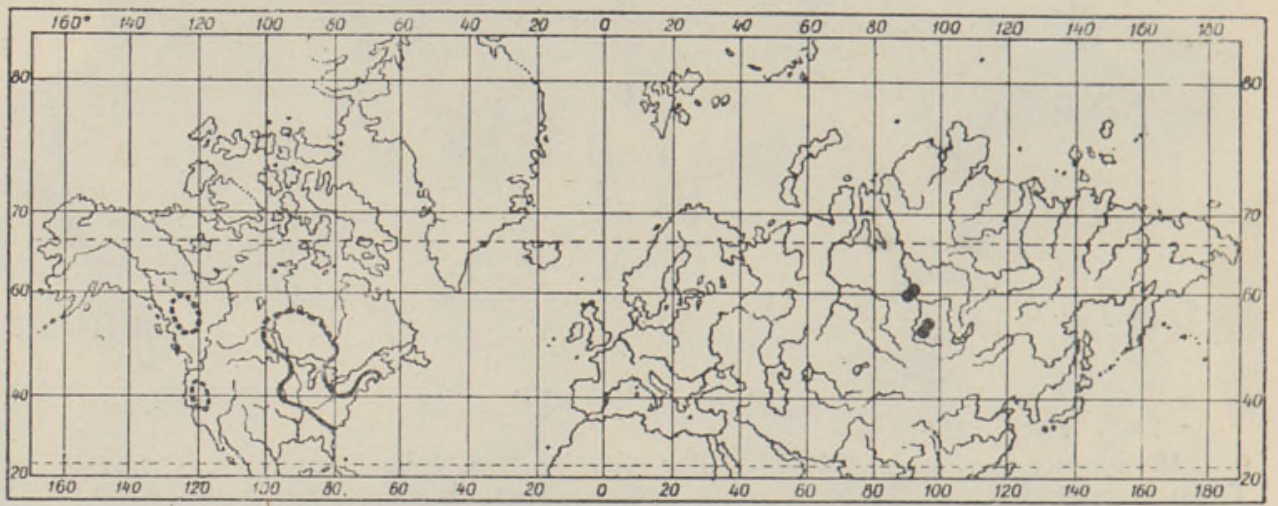

Рис. 9. Распространение Meruliopsis semitincta.

Ареал M. semitincta очень своеобразен (рис. 9). Мы не знаем ни одного трутового гриба, который встречался бы только в Сев. Америке и в Сибири, отсутствуя в Европе. Известно, что грибная флора Сибири имеет больше-сходства с флорой восточной части Сев. Америки, чем с более близкой западной ее частью; при этом «соединительным звеном» распространения является Европа. Чем же обусловлен такой разобщенный ареал $M$. semitincta?

Ясно одно: M. semitincta - вид очень древний и примитивный, стоящий на границе семейств Meruliaceae и Polyporaceae. Связь между этими семействами будет рассмотрена автором в другой, специальной статье; здесь укажем только на то, что у M. semitincta особенно ярко выражается характерная черта рода Meruliopsis: гимений типа Merulius (т. е. сплошной гимений, покрывающий и складки гименофора), наблюдаемый у молодых плодовых тел, переходит в онтогенезисе плодовых тел в тип «Poria» (у которого края трубочек стерильные). Иными словами: как и другие виды рода Meruliopsis, M. semitincta «переходит» в онтогенезисе от семейства Meruliaceae к семейству Polyporaceae.

Исходя из древнего возраста $M$. semitincta, можно предполагать, что участки нынешнего его ареала в Сибири и в Сев. Америке представляют собой остатки древнего обширного ареала. При этом между сибирскими и североамериканскими популяциями наблюдается некоторое расхождение: y первой гифы плодового тела всегда без пряжек, а у второй они снабжены более или менее редкими пряжками (ср. Lowe, 1946; Baxter, 1939). 


\title{
ЛИТ Р Р Т У Р А
}

В а с ил ьков Б. П., 1958. О виде у шляпочных грибов. Проблема вида в ботанике I. М.-Л.

Г] а р м асто Э. Х., 1959. Трутовые грибы Эстонской ССР. Споровые растения, внп. 12. М.-Л.

B axter, D. W., 1939. Some Polypores from the Region of Great Lakes X. Papers Michigan Ac. Sc. XXIV.

Jos ser and. M., 1952. La description des champignons supérieurs. Encyclopédie Mycologique XXI. Paris.

Low e, J. L., 1946. The Polyporaceae of New York State (The Genus Poria). Bull. New York State Coll. Forestry XIX, 2.

Pilát, A., 1936-1942. Atlas des Champignons de l'Europe. Ser. B. Polyporaceae. Praha.
Институт зоологии и ботаники
Академии наук Эстонской ССР
Поступила в редакцию
19 III 1959

\section{MŌNEDE HARULDASTE TORIKULISTE LEVIKUST}

\author{
E. Parmasto, \\ bioloogiateaduste kandidaat
}

Resümee

Artiklis käsitletakse kolme haruldasema torikulise viljakehade ehitust, ökoloogiat ja levikut. Inonotus Heinrichii (Pil.) Bond. et Sing. (fotod 1,2; joon. 1,2) esineb Kesk- ja LääneSiberis, Uraalis ning Komi ANSV-s (joon. 3). Viljakehade morfoloogia, anatoomia ning liigi ökoloogia ja leviku pōhjal vōib järeldada, et 1 . Heinrichii on suhteliselt noor liik, mis kuulub I. radiatus (Fr.) Karst. ligidaste liikide rühma. Siia kuuluvad veel $I$. glomeratus (Peck) Murr. ja $I$. polymorphus (Rostk.) Bond. et Sing.; nagu need, nii ka $I$. Heinrichii on eristunud $I$. radiatus'est seoses spetsialiseerumisega. Tōenäoliselt on I. Heinrichii primaarseks substraadiks olnud Abies sibirica puit ja alles hiljem omandas ta võime kasvada ka teistel okaspuudel.

Et ka saprofüütsete torikuliste juures võib uute liikide tekkimine toimuda spetsialiseerumise teel uutele substraatidele, seda tōestab perekondade Inonotus ja Phellinus liikide ja nende vormide võrdlev uurimine. Eriti Ph. igniarius'e (Fr.) Quél. ja sellele ligidaste liikide juures on ilmne, et uute liikide tekkimine toimub spetsialiseerumise ja substraatide (resp. peremeestaimede) ringi laienemise vaheldumise teel.

Tyromyces crustulinus't (Bres.) E. Parmasto (fotod 3, 4; joon. 4, 5) tunti seni ainult Pōhja-Ameerikast, Rootsist ja Soomest; nüüd lisandus uus leid Kesk-Siberist (joon.6), kus ta esineb oletatavasti reliktina. Selle liigi primaarseks substraadiks on nähtavasti kuuskede puit.

Meruliopsis semitincta (Peck) E. Parmasto (foto 5-7; joon. 7, 8), mida seni tunti ainult Pōhja-Ameerikast, on Kesk-Siberis küllaltki levinud (joon. 9). Tegemist on ürgse ja kaunis primitiivse liigiga, mis on siduvaks lüliks sugukondade Meruliaceae ja Polyporaceae vahel: viljakehade ontogeneesis muutub nende hümenofoori merulioidne ehitus Poria-tüübiliseks. Ka M. semitincta Siberi-leiukohad on nähtavasti reliktse iseloomuga. Siberi eksemplarid erinevad Põhja-Ameerika omadest pannalde täieliku puudumise poolest hüüfidel.

Et ühtlustada seente eoste mõōtmete näitamist seente diagnoosides, soovitab autor näidata sulgudes need kōrvalekaldumised tavalistest mõōtmetest, mis esinevad $10 \%$ vaadeldud eostel. Nii tähendaks «eoste pikkus $(5,0)-5,2-6,2-(6,5) \mu »$, et $10 \%$ eostest on lühemad kui $5,2 \mu$ vōi pikemad kui $6,2 \mu$. 


\section{ON THE DISTRIBUTION OF SOME RARE SPECIES OF POLYPORACEAE.}

\section{E. Parmasto}

\section{Summary}

The author deals with the construction of fruit-bodies, ecology and distribution of three rare species of Polyporaceae. Inonotus Heinrichii (Pil.) Bond. et Sing. (Photos 1, 2; Figs. 1, 2) occurs in Central and West Siberia, in the Urals and in the Komi A.S.S.R. (Fig. 3). On the basis of the morphology and anatomy of iruit-bodies, as well as considering the ecology and distribution of the species it may be assumed that I. Heinrichii is a comparatively young species belonging to the group related to I. radiatus (Fr.) Karst. Here, too, belong I. glomeratus (Peck) Murr. and I. polymorphus (Rostk.) Bond. et Sing.; as well as the latter, $I$. Heinrichii has differentiated from $I$. radiatus owing to specialization. Probably the primary substrate of $I$. Heinrichii used to be Abies sibirica timber, and only later it obtained the ability of growing on other conifers.

The comparative investigation of the species of the families Inonotus and Phellinus and of their forms proves the fact that a new species may be formed on account of the specialization on a new substrate also with the saprophytic Polyporaceae. Particularly Ph. igniarius (Fr.) Quél, and the species related to it show that the originating of new species is due to the variation of the specialization as well as to the widening of the substrate-circle (resp. hosts).

Tyromyces crustulinus (Bres.) E. Parmasto (Photos 3, 4; Figs. 4, 5), was known, up to the present, only in North America, Sweden and Finland; now a new find has been added to the former, occurring in Central Siberia (Fig. 6) where it is probably a relict. The primary substrate of that species is, evidently, fir-wood.

Meruliopsis semitincta (Peck) E. Parmasto (Photos 5-7; Figs. 7, 8), known up to now only in North America, has quite a wide distribution in Central Siberia (Fig. 9). It is an ancient and rather primitive species, forming a connecting link between the families of Meruliaceae and Polyporaceae: in the ontogenesis of the fruit-bodies the merulioid construction of their hymenophore becomes a Poria-type one. Evidently, the Siberian finds of $M$. semitincta are also of a relict character. The Siberian specimens differ from the North America ones by the total missing of clamps on the hyphae.

In order to standardize the indication of the measurements of spores at the diagnosis of fungi, the author proposes to show in brackets the deviations from the usual measurements, occurring in 10 per cent of the spores investigated. Thus, the indication «length of spores $(5.0)-5.2-6.2-(6.5) \mu$ s would mean that 10 per cent of the spores are shorter than $5.2 \mu$ or longer than $6.2 \mu$.

Academy of Sciences of the Estonian S.S.R., Received Institute of Zoology and Botany 